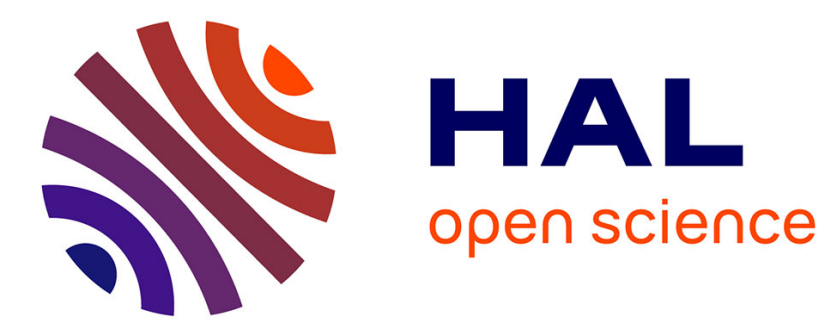

\title{
The moral career of poor patients in free clinics.
}

\author{
Isabelle Parizot, Pierre Chauvin, Serge Paugam
}

\section{To cite this version:}

Isabelle Parizot, Pierre Chauvin, Serge Paugam. The moral career of poor patients in free clinics.. Social Science and Medicine, 2005, 61 (6), pp.1369-80. 10.1016/j.socscimed.2005.02.005 . inserm00083684

\section{HAL Id: inserm-00083684 https://www.hal.inserm.fr/inserm-00083684}

Submitted on 1 Sep 2006

HAL is a multi-disciplinary open access archive for the deposit and dissemination of scientific research documents, whether they are published or not. The documents may come from teaching and research institutions in France or abroad, or from public or private research centers.
L'archive ouverte pluridisciplinaire HAL, est destinée au dépôt et à la diffusion de documents scientifiques de niveau recherche, publiés ou non, émanant des établissements d'enseignement et de recherche français ou étrangers, des laboratoires publics ou privés. 


\section{The Moral Career of Poor Patients in Free Clinics}

Isabelle Parizot*, Pierre Chauvin*, Serge Paugam**

*Inserm U444, 27 rue de Chaligny, 75012 Paris, France

** Lasmas, Iresco, 59 rue Pouchet, 75849 Paris cedex 17, France

Corresponding author:

Isabelle Parizot

Inserm U444, Research team on the Social Determinants of Health and Healthcare Postal address: Inserm U444, 27 rue Chaligny, 75012 Paris, France

Tel: (33) 144738662

Fax: (33) 144738663

Email: isabelle.parizot@u444.jussieu.fr

Serge Paugam

Lasmas, Iresco

Postal address: Lasmas, 59-61 rue Pouchet, 75017 Paris, France

Tel: (33) 140251032

Email:paugam@ehess.fr

Pierre Chauvin

Inserm U444, Research team on the Social Determinants of Health and Healthcare Postal address: Inserm U444, 27 rue Chaligny, 75012 Paris, France

Tel: (33) 144738460

Fax: (33) 144738663

Email: pierre.chauvin@u444.jussieu.fr 


\section{Acknowledgements}

This research was supported by the INSERM Avenir programme, the Institut de l'Humanitaire and Médecins du Monde. Isabelle Parizot and Serge Paugam used the NGO data from an earlier analysis. Our thanks go to Jean-Marie Firdion and Julien Damon for helpful comments and suggestions with this. We also would like to thank the staff at the clinics and all the patients who answered our questions. 


\title{
The Moral Career of Poor Patients in Free Clinics
}

\begin{abstract}
This paper explores the lived experiences and the identity processes attached to attendance at free clinics. It draws on a qualitative study of 94 patients and 37 professionals that were interviewed at four free clinics in France. Since these facilities are for the poor and for people without health coverage, attendance reflects a medical experience as well as an experience of assistance, both of which have an impact on healthcare utilisation. Nevertheless, the meaning attached to the recourse to free clinics and the patients' lived experiences change over time and depend on interactions with clinic staff. This study proposes a typology of care recourse modes (occasional, regular and inconsistent attendance) crossed with different types of lived experiences. Occasional attendance and distant patient-professionals relationships, often due to the humiliation that some people feel when they have to ask for social assistance, characterise the first times people have recourse to care. Patients commit to regular followups only when they have come to terms with their position in the medical and assistance system, doing so by rationalising and adjusting their identity. When discussing our findings, our outlook is to gain greater insight into the utilisation of healthcare by different population groups and in different contexts.
\end{abstract}

Abstract word count: 202 words

Keywords: Healthcare utilisation; moral career; identity; doctor-patient relationship; poverty; France

Full word count: 9193 words 


\section{Introduction}

The whys and wherefores of caring for the poor and the resources for this care are issues that have long been addressed. In Europe, hospitals set up in the Middle Ages focussed primarily on succouring the indigent in a spirit of Christian charity rather than on curing the sick. However, medical establishments did gradually become professionalised. At the same time, the rationale underlying the care of the destitute changed and moved away from its charitable tenet toward principles based on repression, social assistance and later on health insurance (Geremeck, 1987, Foucault, 1973). In France, when the Sécurité Sociale ${ }^{l}$ became widespread during the second half of the twentieth century, the problems of healthcare access for people in social difficulty seemed solved for a while.

In theory, the French welfare system guarantees access to healthcare for anybody residing in the country. However, over the past two decades changing economic structures and family ties have deprived huge segments of the population of the benefits of the welfare and healthcare system (Gallie \& Paugam, 2000). The eighties witnessed the exclusion of some groups from healthcare. Medical and social reasons prompted some patients to forgo healthcare or to go to the emergency rooms at public hospitals, causing overcrowding at these facilities (Chauvin, 2002). This can be explained by the complexity of the social welfare system, the practices and constraints of healthcare professionals, and patients' behaviours. Furthermore, some patients were unable to establish their rights to public health coverage, others did not take the necessary steps to access healthcare while yet others could not afford the medical costs owed by the patient. Consequently, France tailored its welfare system to address the issue of healthcare exclusion. At the same time, humanitarian organisations

\footnotetext{
${ }^{1}$ Sécurité Sociale (called the 'French welfare system' in our paper) is the national welfare system in France that does not only provide health coverage but also includes retirement, maternity benefits, occupational hazards, and so on.
} 
(NGOs) and later the public hospitals set up free clinics (separately from the ER) to provide the poor with medical care (according to a social assistance mode).

NGO free clinics are exclusively for the poor; the other facilities are located at outpatient consultations in public hospitals. Both types of clinics do not ask patients to make any down payments or fill out any administrative forms prior to care. The clinics provide consultations and drugs free of charge and offer social assistance focussed on helping the patient obtain health insurance. The organisation and operations of the free clinic services are especially designed to deal with the intricacy of the medical and social problems of people in precarious situations, something that the public hospital ER is ill-equipped to do (Dodier \& Camus, 1998).

Free clinics have a special role in the French healthcare system since they serve the poor whose entitlement to health coverage has not been acknowledged. Therefore, free clinics provide care that also includes aspects of social assistance. Since the first sociological studies on social assistance, it has been shown that assistance establishes a 'poor person' status (Simmel, 1971). Earlier studies also argue the discreditable nature of assistance since it materialises one's inability to provide for one's needs on one's own and manifests one's dependence. As Coser points out, the very fact of receiving assistance condemns the poor to a specific career, changes their former identity and becomes a stigma influencing their social interactions (Coser, 1965).

However, individuals are never entirely determined by their position in the medical and social assistance system. Even when experiencing a discredited situation, individuals still have some freedom in, and power over their relationship with professionals and in their negotiation of a more gratifying identity (Arkin, 1980) - either within the medical system (Adams et al., 1997; Werner \& Malterud, 2003) or within the welfare system (Paugam, 1991; Snow \& Anderson, 
1987). Dynamic processes are involved since identities are not fixed but changing, especially during social interactions within the institutions (Dubar, 1991).

We focus on how the medical dimension and the social assistance dimension of care in free clinics give rise to specific identity processes and interactions between patients and professionals. Our hypothesis is that attending a free clinic may reinforce a patient's feeling of belonging to an underprivileged category and may influence healthcare behaviours; and that in turn, a patient may develop adjustment and rationalisation strategies to cope with the stigma.

The concept of moral career accounts for an individual's changing situation by addressing its objective and subjective dimensions concurrently. The concept specifically includes the individual's different social positions in light of his or her attitude toward these positions and his or her motivations and desires (Becker, 1963). Several sociologists describe the transformations during individuals' moral careers. In the case of chronic diseases, Bury (1991) underscores how the three phases in the career of a sufferer (i.e., onset; explanation and legitimisation; and lastly adjustment) correspond to an individual's gradual acceptance of the disease and resulting adjustment of his or her identity. In the case of recourse to social assistance, Paugam (1991) shows that at the outset of the trajectory of social declassification, people reject the status of welfare recipient, a rejection prompting them to deploy welfare avoidance strategies. Their attitudes and behaviours start changing as they receive and become increasingly dependent on regular help. Welfare recipients' moral career is then marked by the negotiations of their identity through self-justifications or rationalisations - to a point where they can no longer see their life without the benefit of assistance. Our hypothesis is that similar processes may be at work when poor patients attend free clinics.

The purpose of this article is to understand the evolving relationship with free clinics and changing patient expectations and relationships with the staff, by attaching them to the 
identity and relational processes involved in the recourse to free clinics. We focus on the moral career of free clinic patients and the cycle of changes in the presentation of self to oneself and to others (Goffman, 1961). Thinking in terms of moral career underscores the dynamic aspects of free clinic attendance modes as well as patients' lived experiences. It also emphasises that patients' trajectory is not 'random'; it has direction and milestones.

\section{Material and Methods}

\section{The Survey}

A qualitative sociological survey conducted in four free clinics in the Paris area and in a big provincial city provided the data for our analysis. The main materials were collected over a four-year period (1995 to 1998). During that time, 94 face-to-face interviews were conducted with patients. Individual interviews and group interviews were also conducted with 37 staff members (physicians, nurses, nurse's aides, social workers, and receptionists). The in-depth interviews were completed with non-participant observation at the free clinics, hence providing a deeper insight into the interdependent relations between the patients and the staff. However, this paper is mainly based on our interviews with patients (the other data having been analysed elsewhere, cf. Parizot, 2003).

The interviewers (mainly the first author) contacted the respondent-patients while they were in the waiting room at the clinics or, on rarer occasions, after the patients had seen a physician, a nurse, or a social worker. The interviews lasted an average of 45 minutes (lasting up to two hours and a half when the patient was inclined to share) and took place at the clinics where privacy was preserved. Almost all the interviews were audiotaped and transcribed in full. The interviews explored the patients' relationship with the free clinic, their utilisation of the healthcare and social services, their health perceptions and experiences, and their social situation. 


\section{The Participants}

When the sample was defined, our purpose was not the statistical representativeness of the people attending free clinics. We attempted to build a sample covering all customer profiles, with a focus on gender, age, nationality, health status, and types of recourses. However, the survey was hampered by a linguistic constraint since we did not interview foreigners who couldn't speak French (accounting for a mere 7\% to $13 \%$ of the total attending population according to the clinics). This limitation aside, overall our sample matched the profile of clinic customers. Sixty percent of the respondents were men, average age was 37 , half of the interviewees were foreigners, and the vast majority had precarious housing conditions. Only about one third had their own home and about another third were living more or less temporarily with friends or family; the others were homeless or living at a hotel, in a shelter, or a squat. The interviewees were very different in terms of their health status and reasons for recourse. Some consulted the clinics for occasional, benign disorders; others were treated for chronic disorders (mainly for an HIV infection; but also, in some cases, for cancer). Some were not ill or medically treated on the day of the survey but were there to meet a social worker (who usually handled their request for health coverage) or simply to spend a few hours in a heated, friendly place. Most of the respondents had not been attending the free clinic for long. On the day of the interview, about one third had only been coming for a month or less or had only consulted once. Less than a quarter of the respondents had been coming to the clinic for two years or more.

\section{The Analysis}

Our study is grounded in a comprehensive sociological analysis of the interviews to elucidate the meaning people attributed to their experiences, the way they interpreted their social and health condition and their present and past attendance at the institution. Two authors reread approximately one third of the interviews and methodically discussed their analyses. For each 
interview, our work focused on obtaining a global, comprehensive outlook of the patient's situation in his or her relationship with the free clinic, the medical system and assistance. A similar comprehensive analysis was used to examine the second third of the interviews but the researchers did not systematically confront their views on this part. We were able to highlight different attendance modes at the free clinics and different types of lived experiences by the patients. After our first analyses, the last third of the interviews was conducted and analysed according to Glaser and Strauss's "grounded theory" approach (Glaser \& Strauss, 1967). These interviews allowed us to fine-tune our typology and gain a greater insight into the studied phenomena.

We drew up a typology that emphasises the different attendance modes at free clinics and lived experiences of the recourse to healthcare. As our purpose was to apprehend the patients' own standpoint, their health disorders were not considered a priori as a primary factor in the relationship with the free clinic and its staff.

Furthermore, the retrospective approach adopted during the interviews as well as the comparison of people's discourse at different times during their dealings with the free clinic allowed for the ex post reconstruction of the individuals' trajectories through the institution they attended.

\section{Results}

The respondents' social and medical situations were very different, mirroring the heterogeneity of the situations of precariousness in general. The lack of social protection and meagre financial resources were often what prompted people to go to these clinics. However, very different reasons explain their lack of public health insurance: unawareness of welfare rights; loss of the health coverage entitlement documents; refusal or inability to initiate the formalities to acquire social welfare rights; non-completion of administrative procedures; 
discrimination by the administrative personnel, and so on. Some free clinic patients had medical coverage but their meagre resources prevented them from advancing the medical costs or settling the co-payment. Lastly, a few patients kept going to a free clinic after receiving full coverage for their medical costs either because they felt comfortable at the clinic where a relationship of trust had been forged, or merely because they did not want to change their habits.

Apart from the diversity of the free clinics and their patients, the data analysis identifies three main attendance modes of the clinics: occasional, regular and inconsistent attendance. However, not all patients with the same attendance mode experience attendance in the same way, especially because their recourse occurs at different times during their health trajectory and their career in the health and social assistance systems. Consequently, we distinguish two or three types of lived experiences for each attendance mode (see Table 1). Each type of lived experiences reflects a special adjustment mode to the experience of resorting to a free clinic.

\section{Table 1. Typology of the attendance modes and lived experiences}

The typology should be looked at dynamically. After a time spent discovering the services - a period characterised by occasional attendance - some patients settle into regular attendance. Others maintain their relationship with the institution, albeit inconsistently. Actually, the utilisation modes of the available services and the manner in which the recourses are experienced do change for each patient according to the time spent at the clinic, the patient's changing social condition and health status, but also according to a patient's "identity work" and to the changing meaning the patient attributes to the attendance. The diversity of behaviours and ways of coping with the discredited recourses may be interpreted as different stages in the process of resorting to institutional care. 


\section{Occasional Attendance at Free Clinics}

Occasional attendance at free clinics concerns people whose health does not require longterm medical follow-up or who have only been attending the facility for a short time. When they come to a free clinic, they usually have specific medical requirements. Their relationship with the free clinic is mainly based on medical care. The patients appreciate the opportunity of free care and the benefit of occasional social services, such as assistance in obtaining social protection or sorting out administrative procedures. However, they do not expect the complete management of their problems either because they do not think they need it or because they do not dare ask for it. Two types of lived experiences of occasional attendance are distinguished: humiliation and pragmatism.

The experience of humiliation stems from the shame felt by some when they have to ask for free care. It runs contrary to their reference values of financial self-sufficiency. Furthermore, attending a facility for "the poor" or "the excluded" materialises their fall in social standing. So, receiving care at the facility represents the ordeal of status declassification. A 41 year-old woman commented:

"I'm really not used to this and am very... uncomfortable (...) We've never been in this kind of situation, you know, it's... tough! I think. It's like asking for charity."

Another case in point is a 26 year-old man who saw his inability to attend private clinics as a marker of his social declassification:

"I feel like a failure, you see? I feel like a welfare recipient and that if... If I'm alive now, it's thanks to them (...) I'd never thought I'd ever experience anything like this. Because when I arrived in France, the hospitals I went to were private hospitals, if you please!" 
If these people manage to overcome their reluctance and finally ask for free care, it is chiefly due to their fear of worsening health or to the importance they attach to being healthy (primarily so they can work). The medical character of free clinics somewhat abates the discredit attached to assistance and helps them to accept aid more easily. However, so as not to present a "welfare recipient" self to themselves or to others, they attempt to minimise the extent of the aid they receive. Actually, they often postpone their recourse to care and, as far as possible, keep their attendance to a minimum. They limit their requests to the medical field since they do not want to benefit from any of the available social services. At the same time, they are reserved with staff members. This is way of remaining detached from an experience they have trouble assuming and of preserving their dignity by asserting their rejection of a discredited situation.

For instance, a 39 year-old woman who attended a public hospital after attending an NGO free clinic, highlighted how going to the same facility for many different health concerns may be experienced as 'taking advantage'. She explained:

"I had pimples on my arms. I went straight to the pharmacist to get salve, I did this first thing without going to see Médecins du Monde. Because I was seeing the gynaecologist and didn't want to see several doctors at the same time. Seeing one doctor is already too much. (...) I don't want to take advantage."

Importantly, the experience of humiliation occurs at hospitals as well as at NGO-operated clinics. Actually, it is not so much the characteristics of the care facility (and specifically whether or not it is exclusively for the poor) that are felt to confer a stigma as the inability "to manage on their own" without the help of institutional assistance. For instance, this stance was underscored by a 42 year-old man who said:

"If I'm here, it's just because... it's getting worse and worse. And so, that's what I'm saying, it's getting me down (...) But it doesn't have anything to do with other people, 
it has to do with me and how I feel, you know, to have fallen so low... That's what... what's humiliating for me."

For another 43 year-old man, the positive appreciation of the social worker did not quell his deep-seated uneasiness at being assisted:

"I see the social worker - even if he's great - that I can go like everybody else to see (the doctors in hospital). But you know, it's still embarrassing that you always have to be helped by someone as if you didn't exist."

However, not all patients feel that resorting to a free clinic represents a humiliating ordeal. Actually, patients experiencing pragmatism manage to find reasons, which are not selfdemeaning, for their recourse to the clinic, thus enabling them to use the available services pragmatically. Overall, their rationalisation is grounded in a dual outlook. One, they realise that they need medical care. Since health is one of their values, taking steps to remain healthy is "normal behaviour" over and above (or, at least, theoretically over and above) any financial or administrative contingencies and considerations about assistance. Two, they see the institutional aid as temporary. These patients also refuse the long-term status of "welfare recipients" but unlike the people experiencing humiliation, they rationally use the provided aid as a means of "managing" until they are self-sufficient. "The time needed to sort things out," as many of them said. A 30 year-old woman, for instance, explained that she did not feel uncomfortable asking for free care:

"It doesn't bother me. If you're giving me something, why should I feel uncomfortable? (...) For the time being, I need help! But eventually, things'll work out. But for the time being, I'm in need." 
These patients do not see receiving care free of charge as discrediting assistance. A case in point is another 30 year-old woman who talked about her interview with a local social worker who refused to give her the documents required to consult in the public healthcare system:

"I didn't come here to ask for charity but for care! She turned a deaf ear. (...) So after that, I came directly here, to Médecins du Monde because I know that here I'll get care."

Consequently, the patients make use of the services of the social workers at the free clinics whenever they need to and do not attempt to limit the scope or frequency of their recourse to care. However, as long as the attendance remains occasional, the object of their recourse is still chiefly medical care. The manner in which the care is provided is central to their relationship with the free clinic and to their judgement of the facility.

\section{Regular Attendance at Free Clinics}

When health insurance is still not available after several visits or when patients do not want to consult elsewhere, most of them gradually ease into the regular attendance mode. They usually feel that they are being properly cared for, that the reception is welcoming, and that social assistance follow-up is efficient. They feel comfortable at the facilities. All these factors prompt them to settle down into a regular care-management relationship. They then receive medium term medical and social assistance follow-up or go to the free clinic in much the same way as they would go to an ordinary care facility. They become accustomed to receiving easily accessible, free medical care, and to attending the free clinic for all their health problems, even minor ones. (Whereas usually patients in the occasional attendance mode only have recourse to care when they fear they have serious health problems.) We distinguish three lived experiences of regular attendance, which are usually in successive order, and which shape the above-defined moral career: initiation, settling-in, and demanding. 
The initiation phase corresponds to the time spent internalising the operating rules and standards in effect at the facility. Once these are assimilated, the patients become increasingly self-sufficient within the facility. But the initiation phase also involves the social and symbolic aspects entailed by regular attendance at a free clinic. Actually, when attendance lasts over time, patients can no longer justify their recourse by considering it temporary and short-term. Some patients also come to realise their dwindling chances of finding a situation that will soon enable them to dispense with assistance. So, they have to transform the meaning of the care they receive so they can continue to go to the free clinic without gainsaying their values or feeling shame. At the same time, their social and personal identity changes quite quickly. The change is influenced by the features of the clinic and by the staff members' motivations, among others. Particularly in hospital, the staff insist on every citizen's right to care. During the initiation period, patients increasingly tend to define themselves as "entitled" to care and not as "welfare recipients". NGO patients are also touched by volunteers' efforts to develop friendly and respectful human relationships. Patients tend to define themselves and to be defined - as "worthy" of care rather than as "welfare recipients". In both types of clinics, the quality of the care and the welcome turns the process of asking for assistance into a less distressing experience. For instance, a forty year-old man commented:

"You're put down in the administrations where you get zero consideration... Frankly, I feel humiliated when I go there.. [At Médecins du Monde], it's a little bit different. Right away, you feel that the person who... who looks at you, and even, the minute they talk to you: they look at you! (...) Thank goodness things like that exist."

A woman also said:

"The doors are open, they're responsive... they try to give as much help as they can (...) And so, you feel comfortable, you know." 
During the initiation period, the patients perceive the pre-requisites for establishing a good relationship with physicians and other staff members. They adopt - more or less consciously a behaviour that will gain acceptance. For instance, a thirty-five year old man explained how he could get to know the nurses better and feel closer to them:

“It happens over time... You mustn't be aggressive, you mustn't be bad-tempered, you've got to understand people, too! A person can get up on the wrong side of the bed, well I can understand that person. She yells at me, and I wonder, why is she yelling at me? It's the first time... I have to think about it, maybe she has some other problem... you've got to understand that."

Gradually, they get to know the professionals and the professionals get to know them. Patients begin to enjoy meeting several staff members each time they visit. They also realise that it is possible to establish relationships that are not within the strict confines of the technical procedure. Anonymity gradually vanishes. For instance, during her first visits to a free clinic, a 39 year-old woman said that the defining character of the personnel was their "professional dedication". Several months later, she changed her appreciation and said that it was their human qualities:

"I didn't know... Now, I see that their welcome is fantastic. They're all so nice and wonderful!"

After the initiation phase, most patients settle into a regular relationship involving medical and social care management. They now systematically rationalise the help they receive either as citizens entitled to care or as human beings worthy of receiving help (Parizot, 2003). Expressing some sort of justification of assistance helps them overcome their reluctance and break with the detachment they maintained with the staff during the first visits. Personal ties are forged with some of the team members, a factor that places the relationship with the clinic on a symbolic level different from the level of discreditable assistance. The free clinic 
becomes a reference facility for them - a meaningful place in their lives, not only for their health but often for their social life in general. For instance, many patients said that even if they stopped receiving health care, they would go back to the clinic to let the staff know how they were, and "say hello". Actually, our observations as well as the interviews with the professionals show that this happens regularly. For instance, a 30 year-old woman said:

"I like coming here. Even when I was pregnant, I'd often come, not for the care but because it's very hot at my place, I'd come to rest here..."

At this stage in the relationship, the patients pay close attention to what accompanies the therapeutic procedure per se. They often recognise that the provided service is not merely medical. The welcome service and responsive listening gain in importance and are not actually distinguished from the medical function. Sometimes they are even considered as the first contribution of the free clinic. A 50 year-old man who attended the NGO free clinic explained it in these words:

“They've known me here.... For a very long time... (...) Here, they don't only treat the disease but they also deal with the emotional and family situation. We're treated differently. That's what I like (...) Without Médecins du Monde, I think I would have been much more... much more desperate. (...) The word relief comes to mind, it's... it's a key word: Médecins du Monde relieves people."

The care-management relationship often takes shape as a combination of social, medical and psychological support. The patients see it as a sign of responsive listening and of personal respect. The staff-patient interactions become true relationships involving exchange, following the dynamics of reciprocity similar to relationships between friends. This is paramount in a context of social discredit. For instance, we observed that some patients gave staff members a gift in recognition of their aid. Many respondents actually talk about their relationship with the staff in terms of family relationships or relationships between friends or 
family members. It is known that economic precariousness often disrupts social and family ties. In regular attendance, the very isolated find a little of the emotional warmth they no longer find anywhere else.

“Here, it's like my family, you know," said a thirty year-old man.

Another thirty-four year-old said about a volunteer:

"I was depressed... without her, I wouldn't be here anymore. She really did much more than what I imagined they could do, you know. Without... because they did it without me asking (...) in true friendship, really in all friendship."

The words of a fifty year-old man about "his" physician are also meaningful:

"It's not a relationship between a payee and a professional; it's the relationship between someone asking for help and someone ready to help.

When he prescribes a drug for me and I say 'I don't feel well', he says, 'Listen, Quentin...' - because he doesn't call me Sir anymore, you see, I'm telling you so you understand the point we've reached, him and me. He says to me, 'Well, OK, let's try this, if you're not feeling well...' He, he talks to me, he knows how to talk to me, and that, that's important. He said to me, 'OK, let's try, since there's a new product, we'll try it...' (...) I said yes. I agreed because I felt that when I started taking my new drugs and when I told him that they were good, he was happy, as if... as if he had saved his own son from the fire... He was very, very, very happy for me. He waved at me and we snapped fingers, and all that stuff."

The experience of demanding care creates very different relationships between the staff and patients. Similar to what happens during the settling-in experience, this group systematically rationalises its recourse to assistance. However, their patients needs come first and their focus is almost exclusively on their right to assistance, to a point where they are unable to adjust to 
the constraints of the facilities. They become very forthright in demanding care and insist on dictating what sort of care they want and how it should be provided.

In most cases, the people are dealing with serious medical or social problems. Their multiple handicaps are the only things on their mind, so much so that they can see no logical reason for any restriction to their demand for assistance. Specifically, they do not either understand or accept that the facilities may append financial, administrative or organisational constraints to their demands. A case in point is a thirty year-old man who was going to the hospital for the medical follow-up of his HIV infection and for social work:

"Me, I need help with all this. (...) To feel more comfortable because I'm blocked, blocked, blocked, blocked: psychologically speaking, physically speaking, the works! (...) I'm now at a point where I need out and out support. I can't do it on my own. (...) Some people might say to me, "Just go out and get a job," but, of course, I'd like to work at my age! But I am totally unable to go out and get a job. And the disease is to blame for this. It's ruining my life, it's slowly burning my life away... (...) Even so, I have the same rights as everybody else. (...) I shouldn't have any problems! In my opinion, whatever door I knock on, the answer should be 'yes'.",

The man justified his uncouth manner that was misunderstood by the staff members:

“They say, 'Yeah, they're always complaining,' but it's normal for us to complain because we're the only ones going through what we're going through."

The demanding attitude is part of an overall mistrust of institutions in general. This group often has a feeling of being intentionally dispossessed of a legitimate claim. They also fear that they are being denied access to the latest medical innovations - an attitude that, of course, can also be found in people without any particular social problems. Consequently, they tend to ask for or even demand many examinations and drug prescriptions. 
During this phase of the moral career, patients very seldom develop strategies to gain acceptance and appreciation. On the contrary, armed with the conviction of their rights they openly and sometimes bitterly upbraid any staff member who does not work to meet their demands. A woman commented:

"If you don't yell, nothing gets done!"

Another case in point is a twenty-eight year-old man who openly challenged the constraints he had to meet to receive help from the institutions:

'I don't like someone telling me, 'no, today's not the day, buddy...' No! They're here to help people so there's no 'today's not the day, you're not old enough, you don't have this, you don't have that,' you know!"

The patients are also often navigating between their feeling of satisfaction with the quality of the service they receive and the feeling that their needs and desires are not being satisfied. In these conditions, relationships with staff members become strained. The patient's demanding attitude restricts the professionals' margin for initiative and deprives them of the symbolic retributions that are often necessary to keep doing a hard job. A nurse's aide reproached this group of patients in these terms:

"Without so much as a by your leave, they show up and start demanding things as if they were entitled to everything."

In the clinics we studied, few people experience the demanding phase. At the NGO clinics, patients are usually grateful to the volunteers providing services without pay. Since the image of the clinic at the public hospital projects an image of a competent technical facility, the social side of its services is considered as an additional task that the staff is not formally obligated to ensure. Mostly, patients seem to be aware that demanding care and criticising put 
them at risk, i.e., the risk of being shunted to the side-tracks of the assistance system. The man with an HIV infection who was extensively quoted above said:

“You know, I don't want to say anything bad about this hospital. I'm here, so I'd rather shut up about what I see... Because they are caring for me, and that's already something...”

\section{Inconsistent Attendance at Free Clinics}

The third mode of attendance, which we call inconsistent attendance, concerns but a small proportion of the population. It mainly applies to marginal people who have trouble settling into a social-medical assistance facility. Their medical requirements of the free clinics are inconsistent, as testified by a 42 year-old man who said he came to a free clinic because of a "late winter cold." However, when asked whether he had seen a physician, he merely answered:

"I completely lost interest! To tell the truth, I thought about it... and then I had other things to do, the crossword puzzles, hang out..."

Often, the attention they pay to their health or treatment vanishes once the symptoms have disappeared and they have trouble taking the prescribed treatments. Steps recommended by social workers are also seldom taken. Inconsistent attendance should be correlated with their attitudes toward health and medicine; attitudes very dissimilar from the reference standards of the personnel at the medical facilities. The patients often do not attach much importance to the medical milieu's values concerning the requisite behaviours for hygiene, health, and care. On the one hand, these concerns may seem secondary to finding food, shelter, clothes, and resources. On the other hand, living conditions and representations of the body admittedly have an impact on the attention devoted to the body and on the sensitivity to bodily signs 
(Boltanski, 1971; Blaxter, 1990). The decline of self-image caused by exclusion often entails a gradual detachment from one's own body - to the point of blunting the need to look after it.

Actually, the - often huge - differences between the staff and the patients' representations of the time when a physician "must" be seen hamper any stabilisation within the free clinic. The conflicting representations are likely to spark mutual misunderstandings. But above all, marginal people are generally unable to comply with the institutional constraints that would allow them to enter into the sphere of assistance in a regular manner. Of course, some use the social or health services over time but in a disorganised manner. For instance, some resort to a facility for a while. Then, just as the formalities for the social services or medical follow-up are initiated they stop attending for a time, only to resume attendance at a later date, behaving all the while as if they had never stopped coming.

Some patients are even reluctant to comply with the constraints when they find a temporarily satisfactory balance in their marginal lifestyle. This may be called an experience of service instrumentalisation. The people say they are satisfied with their marginal lifestyle, at least for the time being, and reject any assistance that may jeopardise it. Their daily life is organised around a few remunerative activities (odd jobs, begging, makeshift arrangements, and so on) and around the opportunities for obtaining aid. Attendance at a free clinic is part of this approach, since they find access to medicine and occasional help from the social service at the facility. Remarkably, this group uses the services to continue their marginal life. They enjoy receiving help without having to give much back in return. However, medical as well as social follow-up is jeopardised. For instance, after several months a twenty-seven year-old man had still not taken any of the steps, recommended by the free clinic social worker, to obtain health coverage. He stated:

“The future? I take what I can day by day, I don't want to think about the future. I don't want to. Before, I used to make plans. Now... (...) Plans never happen." 
Nevertheless, most of the time inconsistent attendance concerns people who are experiencing the material and moral hardship of extreme precariousness. Although they express the desire to break with their marginality, they are experiencing such disruptions that their instability precludes any regular social and medical follow-up. Their social, medical and sometimes psychological difficulties often seem closely connected. At free clinics, they experience the crisis of marginality. Their recourse serves as stopgaps for different problems in their lives and encompasses more than the medical field strictly speaking. But they find it very hard to benefit fully from the available care and services. They often give up on the goals they set with the physicians or social workers, especially due to the magnitude or duration of the requisite steps. A 27 year-old man admitted that he was too "disorganised" to reach his goal:

"I have a goal but... I don't think I'm making the effort required to meet it. (...) You know, it's like someone who hasn't got anything, well, he finally gets used to not having anything."

The patients do not deal well with the constraints of assistance, especially when the constraints bring them face to face with a reality they find hard to bear. For instance, the same twenty-seven year-old shrewdly explained:

"I'm really in deep shit, I can criticise... A while ago, I got into a row (afterwards I was annoyed with myself) with a social worker [at the free clinic] because... she asked me: what are you doing...? Why did you do this...? So, dig a little deeper and... when you're not OK, you feel like you're under attack."

Whatever the lived experience during inconsistent attendance, the patient's relationships with the staff members are also inconsistent. Because the people in this group do not care much about complying with clinic rules, they might occasionally give in to violence since they often cannot cope with any constraints whatsoever or they suffer from psychiatric disorders, alcohol or drugs problems. Inconsistent attendance upsets and sometimes discourages the free clinic 
personnel not only because of the patients' behaviour but also because instability lowers the chance that the staff's actions will be successful. Nevertheless, it happens that patients do manage gradually to settle into their relationship with the facility because of the attention they receive and the flexibility of the suggested care and services. In such cases, the clinics we studied facilitate this group's entrance into the sphere of assistance and may foster the gradual restructuring of their self through regular and affective relationships with staff members.

\section{Discussion and conclusions}

The purpose of this paper is to propose an instrument for analysing and understanding the sociological processes at work during attendance at free clinics. Depending on patients' health status and social conditions and on the way they perceive their own situation, they do not have the same expectations of free clinics. This can be seen in their interactions with the staff. We distinguish three modes of attendance in our analysis and different types of lived experiences for each mode of attendance (each mode refers to several types of lived experiences depending on the way a patient rationalises his or her recourse to the free clinic). But since situations and perceptions do change, free clinic attendance is worth considering as a stage in a trajectory. Our analysis emphasises the dynamic nature of the relationship with free clinics.

When people contact free clinics, their attendance mode is usually occasional. Whether they experience their recourse as a humiliating experience or a pragmatic experience, they only attend the free clinic occasionally and do not get much involved in relationships with staff. When recourse lasts over time, most patients settle into regular attendance. Others continue to go to the free clinic but their attendance is unstable. Two types of lived experiences are distinguished for this inconsistent attendance mode: the instrumentalisation of the available services and the crisis of marginality. Our analysis also shows that the three types of lived experiences for regular attendance (initiation, settling-in and demanding) are the three phases 
of a destitute patient's moral career. Although we use the term career, we do not adopt a determinist approach to the trajectories within the free clinics. Not all the individuals experience every phase of the career and the borders between the different career phases are blurred. The object is to understand the changing relationship with the free clinics concurrently with the transformation of the patient's representations, realising, of course, that while some people settle into the career of poor patient, others break with this pattern. This is specifically the case of people who interrupt their recourse to the free clinic because they no longer feel the need to consult a physician or because they now can afford to consult elsewhere.

One limit of our study may be that it deals with a longitudinal approach drawing on crosssectional interviews. However, the extended presence of one author at the hospital free clinic enabled us to monitor the changing situation of several patients through informal interviews. Importantly, during every interview, the respondents were asked to elaborate on any changes they had experienced since their first visits. The analysis of their retrospective explanations and the comparison of lived experiences of people at different times during their trajectories provide an insight into the transformation principles of the experiences - as can be seen in the many studies on moral careers, biographies or life cycles (Thomas, 2003; Auerswald \& Eyre, 2002).

Second, the description and understanding of inconsistent attendance at the free clinics is a bit limited as there were few interviews with people concerned by this attendance mode. However, we have further grounded our analysis in the literature on this subject.

Our study clearly shows that as long as the benefit of institutional aid is experienced as a failure and as a demeaning ordeal, patients attempt to restrict their use of the clinics. Patients want their attendance at the free clinic to be temporary and see it as such. The relationships with the staff are detached, strictly professional, and limited to the requirements of medical 
care strictly speaking. On the other hand, when patients are able to re-interpret and rationalise their recourse to assistance, their attendance is no longer determined by the need to distance themselves from the stigma attached to using a free clinic. Settling into social-medical assistance usually concerns people with major medical or social problems that prevent them from consulting elsewhere. During regular discussions between recipients and staff, they become better acquainted and their mutual recognition goes beyond their respective statuses in the institution. The former are no longer reluctant to use the different available services and appreciate the moral support (particularly invaluable as they are experiencing social hardship) expressed through personal and affective relationships. In itself, the quality of the relations becomes another factor contributing to the patient's rationalisation of his/her attendance at a free clinic.

Actually, the action of free clinics materialises a relationship of assistance, i.e., the meeting between an individual with a discredited social status with another individual in charge of helping him or her on behalf of, and within an institution. Therefore, the utilisation of the services depends on the ability of individuals to cope with the discredit of assistance and negotiate the constraints of dependence, and on their denial or acceptance of the social identity that assistance establishes. The different stages of a poor patient's moral career match the changing adjustment modes to this discreditable experience. Only once patients accept their position in the medical and assistance system, can they fully benefit from regular medical and social follow-ups.

From this standpoint, the results may not be limited to the clinics in our study but encompass the fundamental principles of the relationship with a service-providing institution and its staff, especially when the provided care and services materialise a discredit. Notably, the typology developed for this paper coincides with Paugam's analyses of lived experiences during recourse to social assistance centres (Paugam, 1991). At these centres as at free clinics, 
adjustment modes to status degradation are materialised by comparable avoidance strategies when dependence is not very high, then by "optimum" utilisation of the services when dependence is high and individuals start rationalising their experience. Studies of other contexts show a correlation between the acceptance of one's status and the nature of one's relationships with professionals. For instance in AIDS shelters, the involvement in the life of the residence and in the relationships with the other residents and the professionals depends on the acceptance of one's condition as an ill person (Rosman, 1999).

In this paper, we present the experiences of poor patients without explicitly referring to the type of health problems they have. Of course, their modes of attendance and experiences depend on their health status. Actually, poor patients follow several intertwined trajectories: health trajectory, sufferer trajectory, treatment and medical utilisation trajectories, the trajectory through assistance institutions, trajectory through the free clinic, and so on. The lived experiences in each of these fields often influence the lived experiences on the outside. Passing from one phase to another of the moral career is influenced by the change in the person's career in other areas. For instance, the humiliation phase experienced by some during their first visits is shorter or even non existent when the person has already received social assistance and is able to rationalise the earlier help received from another welfare institution (for instance, by referring to the principles of national solidarity and by assuming the attitude of a person entitled to care). Also, a worsening pathology may hasten the phase of settling in, or even foster the radicalisation of attitudes toward care and services and spark the demanding phase.

In any case, our approach (which does not focus a priori on studying the patients' career regarding their health status) makes it possible to understand how a trajectory within a care facility meets more than merely medical criteria. Our results demonstrate how important it is 
to take into account the implications of the utilisation of care in terms of social status and identity.

Overall, we show the relevance of analysing individuals' lived experiences to understand their utilisation of the available services in the institutions. Our results argue that the consequences of the recourse to care on a person's identity should be integrated into the explanatory models of healthcare utilisation (but also, maybe, of drug utilisation and compliance). Actually, these consequences influence patients' satisfaction and acceptance of the available care and services. Our results may also shed light on the issue of low care consumption by underserved populations (Auvray et al., 2001; Asch, 2000) - including the under-use of the clinics designed for them (a fact that professionals and researchers often underscore; for example, Klein et al., 2000). Based on a quantitative survey conducted at free clinics, we show that people experiencing humiliation run a higher risk of forgoing care and drugs than people experiencing settling-in (Chauvin \& Parizot, 2003).

However, our results may also be useful for understanding recourse in other discredited situations, for instance the case of medical follow-ups for HIV infections (Fife, 2000). It is known that illness disrupts the sufferer's social integration and identity (Charmaz, 1991; Williams, 1984; Anderson \& Bury, 1988). However, the recourse to care in itself may also emphasise or even materialise in the eyes of the ill person and in the eyes of others a spoiled identity and thus disrupt the person's recourse. On the other hand, appropriate, attentive care fostering social ties may improve patients' assumption of care and adherence to treatments (Chauvin, Mortier, Carrat et al., 1997; Roter \& Hall, 1992), as has been shown for instance in several studies on HIV-AIDS.

Our research has also implications for professionals' practices. If patients are to assume their health or social problems, health professionals should be careful not to attach any stigma to recourse, or even to suggest a non-discredited meaning to the care. This is specifically the 
case for occasional attendance and for the initiation phase of regular attendance. For the group that attends the care facilities inconsistently, our analyses suggest that the right to a marginal lifestyle claimed by some should be considered. Admittedly, expressing the choice of a marginal life seldom corresponds to a real control over one's entire social trajectory. But since this group rejects any type of assistance likely to restrict their freedom, the recognition of its expectations is often vital so that the conditions of care management do not erect a barrier to their medical and social follow-up.

In conclusion, the results of this study as other findings reported in literature clearly underscore how much therapeutic behaviours involve domains other rather than the strict medical field. The recourse to care depends on the social and personal identities of the individuals, their daily social relationships, and the interactions at the care facility. However, at the same time, the recourse to medical care in itself has repercussions on a patient's identity and social ties. This should not be overlooked since a patient will anticipate the repercussions and adopt his or her therapeutic behaviour accordingly.

\section{References}

Adams, S., Pill, R. \& Jones, A. (1997). Medication, chronic illness and identity: the perspective of people with asthma. Social Science \& Medicine, 45, 189-201.

Anderson, R., \& Bury, M. (eds.) (1988). Living with chronic illness: the experience of patients and their families. London: Unwin Hyman.

Arkin, R. (1980). Self presentation. In D. Wegner and R. Vallacher (eds). The Self in Social Psychology (pp. 158-182). New York: Oxford University Press.

Asch, S. M., Sloss E. M., et al. (2000). Measuring underuse of necessary care among elderly Medicare beneficiaries using inpatient and outpatient claims. Jama 284(18), 2325-2333. 
Auvray, L., Dumesnil, S., \& Le Fur, P. (2001). Santé, soins et protection sociale en 2000. Paris: Credes.

Auerswald, C. L. \& Eyre S. L. (2002). Youth homelessness in San Francisco: a life cycle approach. Social Sciences and Medicine, 10, 1497-1512.

Becker, H. S. (1963). Outsiders; Studies in the sociology of deviance. New York: Free Press, 1963

Boltanski, L. (1971). Les usages sociaux du corps. Annales, 1, 205-233.

Blaxter, M. (1990). Health and Lifestyles. London: Tavistock/Routledge.

Bury, M. (1991). The sociology of chronic illness: a review of research and prospects. Sociology of Health and Illness, 13, 451-468.

Charmaz, K. (1991). Good Days/Bad Days: The Self And Time In Chronic Illness. New Brunswick: Rutgers University Press.

Chauvin, P., ed. (2002). Prevention and Health Promotion for the Excluded and the Destitute in Europe. Amsterdam: IOS Press.

Chauvin, P., Mortier, E., Carrat, F., Imbert, J.C., Valleron, A.J., \& Lebas, J. (1997). A new out-patient care facility for HIV-infected destitute populations in Paris, France. Aids Care, 9, 4: $451-459$.

Chauvin, P. \& Parizot, I. (2003). The access to care of underserved populations: a research among free clinics patients in the Paris area. Rev Epid Sant Pub (in press).

Coser, L. A. (1965). The Sociology of Poverty. Social Problems, 13, 140-148.

Dodier, N. \& Camus, A. (1998). Openness and specialisation: dealing with patients in a hospital emergency service. Sociology of Health and Illness, 20, 413-444. 
Dubar, C. (1991). La socialisation: construction des identités sociales et professionnelles. Paris: Armand Colin.

Fife, B., \& Wright, E. (2000). The dimensionality of stigma: A comparison of its impact on the self of persons with HIV/AIDS and cancer. Journal of Health and Social Behavior, 41, $50-67$.

Foucault, M. (1973). Birth of the clinic. New York: Pantheon.

Gallie, D., \& Paugam, S. (2000). Welfare regimes and the experience of unemployment in Europe. Oxford: Oxford University Press.

Geremek, B. (1987). La potence ou la pitié. L'Europe et les pauvres du Moyen Age à nos jours. Paris: Gallimard.

Glaser, B. \& Strauss, A. (1967). The discovery of grounded theory: strategies for qualitative research. New York: Adline.

Goffman, E. (1961). Asylums: Essays on the Social Situation of Mental Patients and Other Inmates. New York: Doubleday Anchor.

Klein, J. D., Woods, A. H., Wilson, K. M., Prospero M., Greene J., \& Ringwalt, C. (2000). Homeless and Runaway Youth's Access to Health Care. Journal of adolescent health, 27, 331-339.

Parizot, I. (2003). Soigner les exclus, Identités et rapports sociaux dans les centres de soins gratuits. Paris: Presses Universitaires de France.

Paugam, S. (1991). La disqualification sociale. Essai sur la nouvelle pauvreté. Paris: Presses Universitaires de France.

Rosman, S. (1999). Sida et précarité. Une double vulnérabilité. Paris: L’Harmattan. 
Roter, D. L., \& Hall J. A. (1992). Doctors talking with patients/patients talking with doctors: Improving communication in medical visits. Westport: Auburn House.

Simmel, G. (1971). The Poor. In D.N. Levine (Ed.), Georg Simmel. On individuality and social forms (pp.150-178). Chicago: University of Chicago Press.

Snow, D. A., \& Anderson, L. (1987). Identity Work Among the Homeless: The Verbal Construction and Avowal of Personal Identities. American Journal of Sociology, 92, 13361371.

Strauss, A., Schatzman, L., Bucher, B., Ehrlich, D., \& Sabshin, M. (1963). The hospital and its negotiated order. In E. Freidson (Ed), The hospital in modern society (pp. 147-168). New York: The Free Press.

Thomas, H. (2003). Pregnancy, illness and the concept of career. Sociology of Health \& Illness, 25, 383-407.

Weber, M. (1968). Economy and Society. New York: Bedminister Press.

Werner, A., \& Malterud, K. (2003). It is hard work behaving as a credible patient: encounters between women with chronic pain and their doctors. Social Science \& Medicine, 57, 14091419.

Williams, G. (1984). The genesis of chronic illness: narrative reconstruction. Sociology of Health and Illness, 6, 17, 5-200. 
Table 1. Typology of attendance modes and lived experiences

\begin{tabular}{ll}
\hline \multicolumn{1}{c}{ Attendance Mode } & \multicolumn{1}{c}{ Type of lived experiences } \\
\hline I. Occasional attendance & I.1- Humiliation \\
& I.2- Pragmatism \\
II. Regular attendance & II.1- Initiation to regular care \\
& II.2- Settling into a care-receiving relationship \\
& II.3- Demanding for care \\
III. Inconsistent attendance & III.1- The instrumentalisation of the available \\
& services \\
& III.2- Crisis of marginality \\
\hline
\end{tabular}

